\title{
Correction to: Impact of actual waiting time and perceived waiting time on treatment satisfaction in patients receiving outpatient diabetes care
}

\author{
Shiori Toga-Sato ${ }^{1} \cdot$ Takahiro Tosaki $^{1} \cdot$ Masaki Kondo $^{2} \cdot$ Shin Tsunekawa ${ }^{2} \cdot$ Yoshiro Kato $^{2} \cdot$ Jiro Nakamura $^{2}$. \\ Hideki Kamiya $^{2}$
}

Published online: 27 January 2021

(C) The Japan Diabetes Society 2021

\section{Correction to: Diabetology International https://doi.org/10.1007/s13340-020-00486-y}

In the original publication of the article, in Tables 2 and 3, p-values should be replaced with No.of patients. The correct Tables 2 and 3 are provided below.

The original article has been corrected.

Publisher's Note Springer Nature remains neutral with regard to jurisdictional claims in published maps and institutional affiliations.

The original article can be found online at https://doi.org/10.1007/ s13340-020-00486-y.

Shiori Toga-Sato secretary@tosaki.jp

1 TDE Healthcare Corporation TOSAKI Clinic for Diabetes and Endocrinology, 2-1007, Motoueda, Tenpaku ward, Nagoya, Aichi 468-0009, Japan

2 Division of Diabetes, Department of Internal Medicine, Aichi Medical University School of Medicine, 1-1, Yazakokarimata, Nagakute, Aichi 480-1195, Japan 


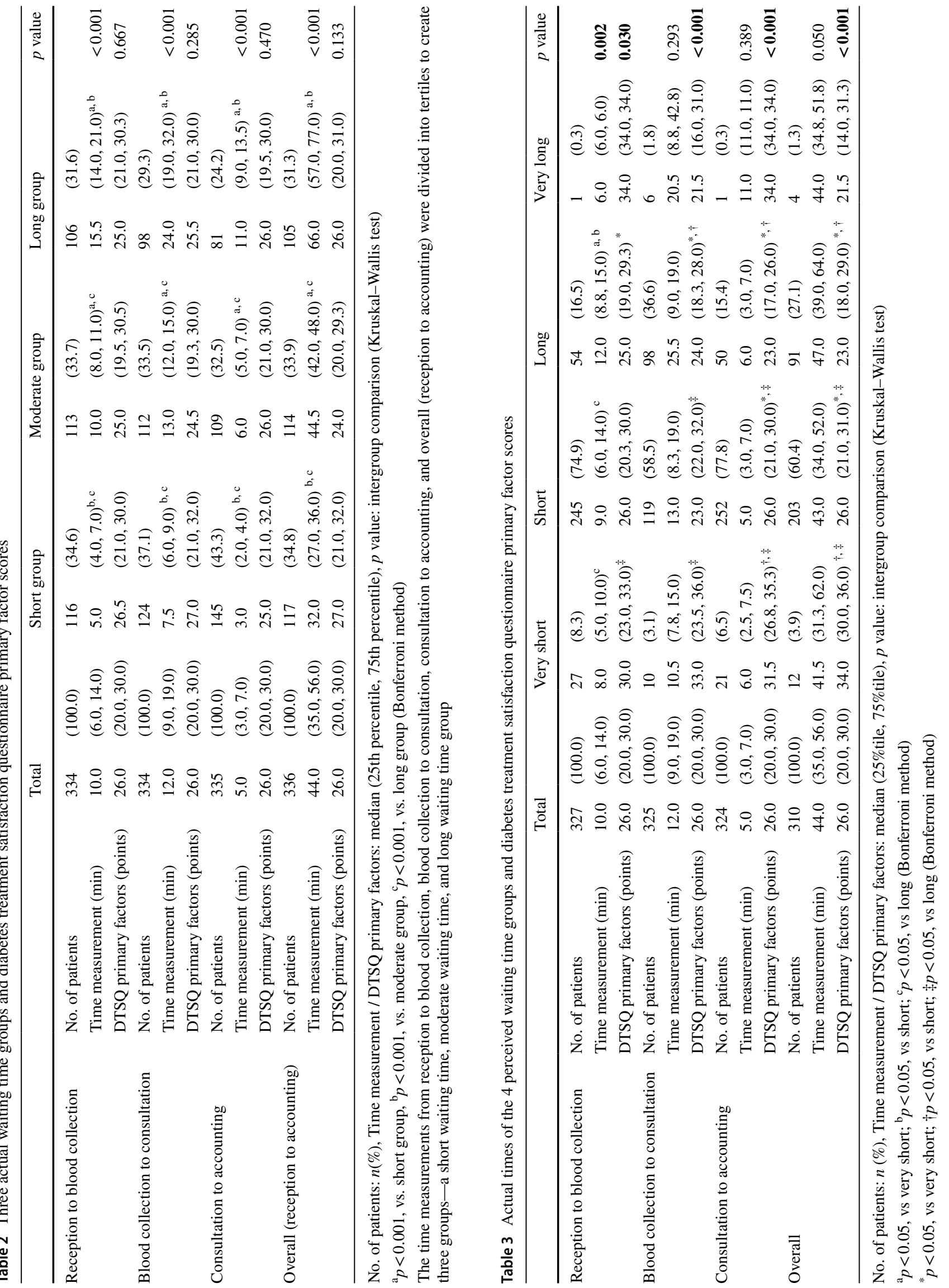

